\title{
Article
}

\section{The Role of Ancestral Duplicated Genes in Adaptation to Growth on Lactate, a Non-Fermentable Carbon Source for the Yeast Saccharomyces cerevisiae}

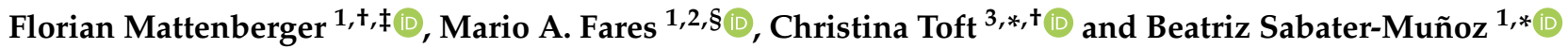 \\ 1 Integrative and Systems Biology Group, Department of Abiotic Stress, Institute for Cellular and Molecular \\ Biology of Plants (IBMCP) from the Spanish National Research Council (CSIC), Polytechnic University of \\ Valencia (UPV), 46022 Valencia, Spain; florian.mattenberger.1@ulaval.ca \\ 2 Department of Genetics, Smurfit Institute of Genetics, University of Dublin, Trinity College, Dublin 2, Ireland \\ 3 Panomics and Evolutionary Systems Microbiology Group, Program Systems Biology of Molecular \\ Interactions and Regulation, Institute for Integrative Systems Biology (I2SysBio), Joint Institute of the Spanish \\ National Research Council (CSIC), Universidad de Valencia (UV), 46980 Paterna, Spain \\ * Correspondence: christina.toft@csic.es (C.T.); bsabater@ibmcp.upv.es or b.sabater.munoz@csic.es (B.S.-M.) \\ + Equal contribution. \\ $\ddagger$ Actual address: The Landry Lab, Institut de Biologie Intégrative et des Systèmes (IBIS), University of Laval, \\ Québec, QC G1V 0A6, Canada. \\ $\S$ Posthumous author.
}

Citation: Mattenberger, F.; Fares, M.A.; Toft, C.; Sabater-Muñoz, B. The Role of Ancestral Duplicated Genes in Adaptation to Growth on Lactate, a Non-Fermentable Carbon Source for the Yeast Saccharomyces cerevisiae. Int. J. Mol. Sci. 2021, 22, 12293. https:// doi.org/10.3390/ijms222212293

Academic Editor: Daniela Fiocco

Received: 22 October 2021

Accepted: 11 November 2021

Published: 14 November 2021

Publisher's Note: MDPI stays neutral with regard to jurisdictional claims in published maps and institutional affiliations.

Copyright: (c) 2021 by the authors. Licensee MDPI, Basel, Switzerland. This article is an open access article distributed under the terms and conditions of the Creative Commons Attribution (CC BY) license (https:// creativecommons.org/licenses/by/ $4.0 /)$.
Abstract: The cell central metabolism has been shaped throughout evolutionary times when facing challenges from the availability of resources. In the budding yeast, Saccharomyces cerevisiae, a set of duplicated genes originating from an ancestral whole-genome and several coetaneous small-scale duplication events drive energy transfer through glucose metabolism as the main carbon source either by fermentation or respiration. These duplicates ( a third of the genome) have been dated back to approximately $100 \mathrm{MY}$, allowing for enough evolutionary time to diverge in both sequence and function. Gene duplication has been proposed as a molecular mechanism of biological innovation, maintaining balance between mutational robustness and evolvability of the system. However, some questions concerning the molecular mechanisms behind duplicated genes transcriptional plasticity and functional divergence remain unresolved. In this work we challenged S. cerevisiae to the use of lactic acid/lactate as the sole carbon source and performed a small adaptive laboratory evolution to this non-fermentative carbon source, determining phenotypic and transcriptomic changes. We observed growth adaptation to acidic stress, by reduction of growth rate and increase in biomass production, while the transcriptomic response was mainly driven by repression of the whole-genome duplicates, those implied in glycolysis and overexpression of ROS response. The contribution of several duplicated pairs to this carbon source switch and acidic stress is also discussed.

Keywords: whole-genome duplicates; small-scale duplicates; phenotypic response; metabolic distance; acidic stress; reactive oxygen response; heat-shock proteins

\section{Introduction}

Saccharomyces cerevisiae, the budding yeast, uses glucose as its main carbon source to obtain energy, as with many other organisms. Similar to numerous other yeast species, it can alternate between fermentative and oxidative metabolism, depending on the availability of glucose and oxygen [1]. In addition, this species is able to use alternative carbon sources by adapting growth profiles [2]. This growth adaptation/versatility has been of high interest for biotechnology, from the fuel industry to biomedical/pharmaceutical industries, driving the interest in metabolism adaptation through genome modifications (i.e., adding new transporters or enzymes from closely related species or bacterial species of interest) (reviewed in [3]). This interest also relies on the tolerance to industrial bioprocess 
conditions, on which the yeast should be able to respond to environmental challenges or stress factors (i.e., acidic conditions, ethanol concentration, low or high temperatures) including increased concentrations of the selected compound. Under these bioprocessing conditions, yeasts might not be alone; they interact with other cells and sometimes with other species, increasing selective forces in such environments and intrinsically modifying stress responses. Indeed, it has been recently postulated that stress-free microbes lack vitality (reduced growth ability, reproduction, and longevity), indicating that any organism can cope with stressing conditions through multiple layers of response that is being driven and shaped by its genome [4] (and references within). How then does the yeast respond to these environmental challenges?

Around 100 MYA, a hybridization event took place between two different ancestral yeast species at the same time as the appearance of the first flowering plants, which established the new nectar (sugars) environments [5-7]. The resulting hybrids restored its fertility, with its genome reshaped by this whole-genome duplication (WGD) event followed by genome reduction and by numerous small-scale duplication (SSD) events, giving rise to glucose alcoholic fermentation metabolism and glucose-mediated repression (Crabtree effect) to cope with the new energy source environment, the hexose-sugar based nectars [8,9]. Saccharomyces cerevisiae is one of the descendants of this ancestral hybridization event, currently maintaining a third of its genome in duplicate $[5,6,10]$. In more recent works, it has been demonstrated that hybridization events among wine yeasts are produced mainly through rare mating types, giving rise to new hybrids with differential duplicated chromosome retention linked to adaptive functional innovation [11-13]. These works support the prevalence of duplicates and innovative potential as proposed more than fifty years ago by Ohno [14]. Since then, the molecular mechanisms behind this innovative potential and duplicate retention have become the target of many other researchers, involving the study of transcriptomic divergence between copies, functional specialization, adaptive potential, and evolvability of duplicates, among other parameters in all life kingdoms [15-23]. Some of these latest works show a relationship between duplicate transcriptional divergence and transcriptional plasticity in response to environmental challenges, which may link the evolvability of duplicates and their functional innovative potential in yeasts [23-26]. In recent years, we have been able to demonstrate the role of these ancestral duplicates in the stress response when challenging the budding yeast to alternative non-fermentable carbon sources, such as glycerol and ethanol [26,27]. Allowing us to unveil a common mechanism for both types of stresses, as both molecules (glycerol and ethanol) not only impose a change in carbon source, but they also induce other stresses such as osmotic pressure under low water activity and abiotic factors. We wanted to ascertain whether there is a common signature for all kinds of stresses that affect yeast growth, and how ancestral duplicates are involved in such signatures.

Skoneczny and Skoneczna [28] reviewed the response mechanisms to chemical and physical stresses in several species of yeast, including S. cerevisiae, and their response to acidic conditions [28]. At low extracellular $\mathrm{pH}$, the protonated form can cross the cell membrane by simple or facilitated diffusion, whereas at the cytosol, the physiological $\mathrm{pH}(\sim 7.0)$ induces carboxylic acid dissociation into acid anions inducing acidic stress. This acidic stress can be counteracted by the organism stress response by activating $\mathrm{H}+$ -ATPases or multidrug transporters that pump out the acid anions [28-31]. However, little attention has been paid to the reactive oxygen species (ROS) response, the involvement of chaperones, or to the implication of duplicated genes, when cells were faced with the usage of these non-fermentable molecules as the energy source.

The main aim of this work was to unveil the implication of duplicated genes in the use of lactic acid as the sole carbon source while also facing acidic stress in the yeast $S$. cerevisiae. From the phenotypic point of view, we found that the growth rate was negatively affected, whereas biomass production was increased after a short adaptive process. This phenotypic change correlates with expression changes to the use of lactic acid/lactate as the nonfermentable carbon source, being the transcriptomic response mainly driven by ancestral 
duplicates, especially by WGDs. This transcriptomic response induced a cellular response that explains the observed phenotypic changes, and highlights the importance of other stress responses, such as ROS response similar to those observed with osmotic or ethanol stresses, or the chaperone implication at the adaptive process. These aspects are discussed in this paper.

\section{Results}

\subsection{Lactic Acid as a Non-Fermentable Carbon Source Affects S. cerevisiae Growth Parameters}

To test the ability of the yeast to overcome a challenge with a non-fermentable carbon source as lactic acid/lactate, the yeast Saccharomyces cerevisiae strain Y06240 was evolved first through a daily $1 \%$ bottlenecking in YPD for 100 passages ( 6.6 generations per passage; $\sim 660$ generations). One of the evolved populations was then selected and subjected to ALE (adaptive laboratory evolution) to YPL (stressing media with 1\% yeast extract, $2 \%$ peptone, and 3\% lactic acid as the sole carbon source, at $\mathrm{pH} 5.5$ ) by daily passages of $10 \%$ of the population for another 10 passages ( $\sim 3.3$ generations per passage; $\sim 33$ generations on adaptive evolution), also maintaining a control line in YPD under the same conditions; both lines were in triplicate. After evolution, cells from the fossil records at different time points were recovered and subjected to phenotypic characterization through determination of growing parameters with Bioscreen c, and transcriptomic profiling by RNAseq (Figure 1A; see Material and Methods Section for further details).

We determined the maximum growth rate (r, Figure 1B, and Supplementary Materials Figure S1A) and carrying capacity (k, Figure 1C and Supplementary Materials Figure S1B) for each population in the evolved and challenged media (YPD and YPL), from $\mathrm{OD}_{600}$ time course $\log _{2}$-adjusted model as implemented in Growthcurver [32]. Both parameters were used as a measurement of the populations' fitness in each medium. The starting yeast population $\left(\mathrm{t}_{0}\right)$ showed a sigmoidal $\mathrm{OD}_{600}$ curve with a maximum growth rate $(\mathrm{r} \pm$ s.d.) of $0.261 \pm 0.055 \mathrm{~h}^{-1}$ in YPD and of $0.175 \pm 0.043 \mathrm{~h}^{-1}$ in YPL, being significantly lower in the second as expected due to the acidic stress (Wilcoxon rank test, $p$-value $=0.0175$; Figure $1 \mathrm{~B}$ and Supplementary Materials Figure S1A). The evolved population $t_{100}$ also showed a sigmoidal curve in YPD, but with a lower growth rate of $0.195 \pm 0.049 \mathrm{~h}^{-1}$ (Wilcoxon rank test, $p$-value $=5.83 \times 10^{-4}$ ), and when challenged to YPL growth rate, was even lower $\left(\mathrm{r}=0.141 \pm 0.030 \mathrm{~h}^{-1}\right.$; Wilcoxon rank test, $p$-value $\left.=5.349 \times 10^{-2}\right)$, not observing statistical differences among media at this time point (Wilcoxon rank test, $p$-value $=0.165$ ). At $t_{110}$, the control population (Dat 110 , being evolved in YPD) showed also sigmoidal curve in YPD recovering growth rate $\left(\mathrm{r}=0.257 \pm 0.062 \mathrm{~h}^{-1}\right)$ compared to $\mathrm{t}_{0}$ (Wilcoxon rank test, $p$-value $\left.=5.827 \times 10^{-4}\right)$, but showed a reduced growth rate when challenged to YPL $\left(\mathrm{r}=0.120 \pm 0.016 \mathrm{~h}^{-1}\right.$; Wilcoxon rank test, $p$-value $\left.=4.15 \times 10^{-4}\right)$. Whereas YPL-adapted $\mathrm{t}_{110}$ population $\left(\mathrm{Lat}_{110}\right)$ had reduced growth rate in YPL $\left(\mathrm{r}=0.104 \pm 0.019 \mathrm{~h}^{-1}\right.$; Wilcoxon rank test, $p$-value $\left.=3.04 \times 10^{-6}\right)$ compared to $t_{100}$ challenged to YPL, and showed a higher response when challenged to the ancestral medium, YPD $\left(\mathrm{r}=0.262 \pm 0.032 \mathrm{~h}^{-1}\right.$; Wilcoxon rank test, $p$-value $=3.04 \times 10^{-6}$; Figure 1B).

Interestingly, we observed that carrying capacity $(\mathrm{k})$ showed a positive trend that indicates phenotypic adaptation to the new environment (Figure 1C). At $t_{0}$, carrying capacity was $1.477 \pm 0.039$ in YPD and $1.351 \pm 0.105$ in YPL, being significantly different (Wilcoxon rank test $p$-value $=1.74 \times 10^{-2}$ ). At $t_{100}$, carrying capacity was $1.549 \pm 0.098$ in YPD and $1.576 \pm 0.364$ in YPL, with no significant differences between them (Wilcoxon rank test $p$-value $=0.0728)$. At $t_{110}$, populations showed bigger differences with starting population (Figure $1 \mathrm{C}$ and Supplementary Materials Figure S1B). Control population (Dat ${ }_{110}$ ) had a k of $1.529 \pm 0.050$ in YPD and a $k$ of $1.692 \pm 0.222$ in YPL being significantly different from $t_{0}$ (Wilcoxon rank test, $p$-value $=4.1610 \times 10^{-4}$ in YPD; $p$-value $=1.11 \times 10^{-4}$ in YPL). The YPL-adapted $\mathrm{t}_{110}$ population (Lat 110 ) had $\mathrm{k}$ of $1.677 \pm 0.088$ in YPL and a $\mathrm{k}$ of $1.606 \pm 0.034$ in YPD, being significantly different (Wilcoxon rank test, $p$-value $=8.702 \times 10^{-5}$ ) among media and respect to $\mathrm{t}_{0}$ population (Wilcoxon rank test $p$-value $=7.61 \times 10^{-7}$ in YPL; $p$-value $=1.52 \times 10^{-6}$ in YPD; Figure 1C). 
A

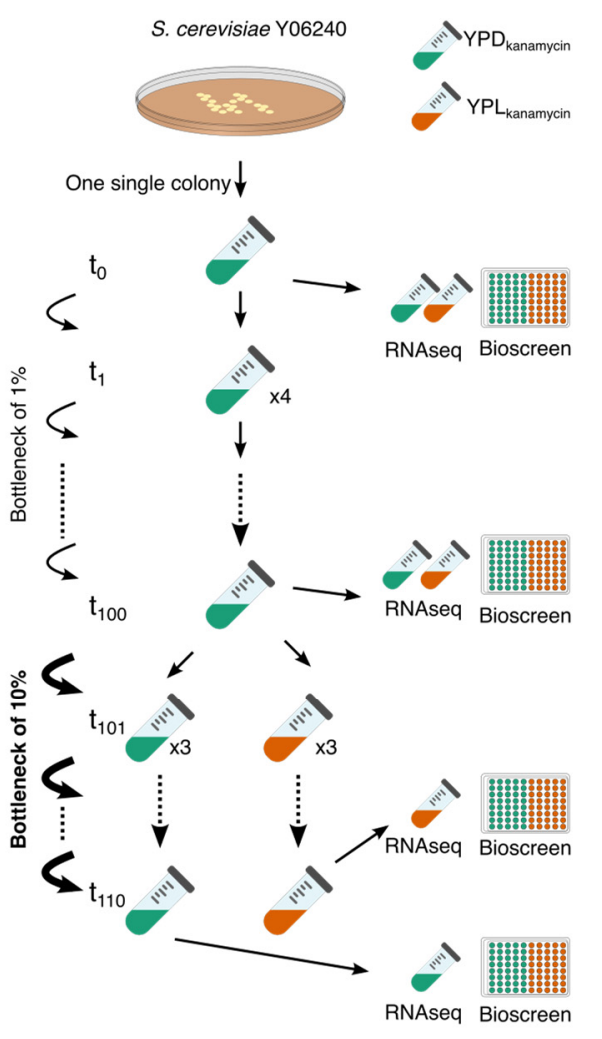

B

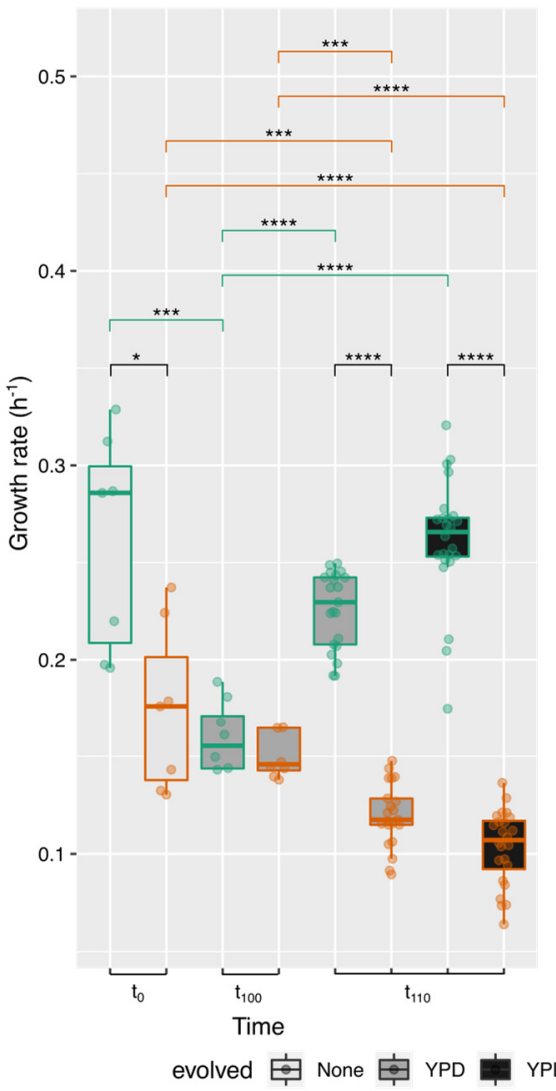

C

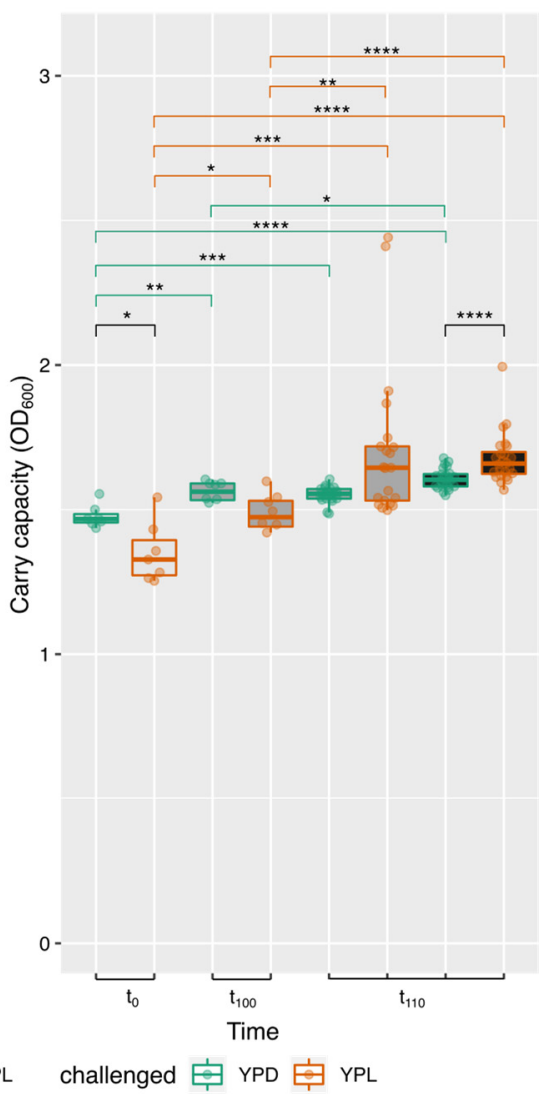

Figure 1. Saccharomyces cerevisiae laboratory evolution under diversification and adaptation to YPL and phenotypic effects on growing parameters. (A) Scheme of experimental evolution setup, with 1\% bottlenecks during the first 100 passages (population diversification stage), and adaptive laboratory evolution to YPL or YPD under 10\% population bottlenecks for additional 10 passages; (B) Growth rate ( $\mathrm{r}$, in $\mathrm{h}^{-1}$, as inferred from Growthcurver) for each time point and lines series, with the indication of the evolved and challenged media, note that the $t_{0}$ populations were not evolved, but reared in YPD medium; (C) Carrying capacity (k), as maximum $\mathrm{OD}_{600}$ (as inferred from Growthcurver) for each time point and lines series, following the same criteria as in (B). Statistical differences among means were determined with ${ }^{*},{ }^{* * * *}$ or ${ }^{* * * *}$ when the probabilities are $p<0.05, p<0.005, p<0.001$, and $p<0.0001$, respectively, using a Wilcoxon rank test.

\subsection{Transcriptional Response of S. cerevisiae to Lactic Acid/Lactate as Non-Fermentable Carbon Source}

The genetic transcriptional response of the yeast cells to a non-fermentable carbon source, as the lactic acid/lactate, was determined by RNA sequencing with comparison between time points and conditions (Figure 1A). The transcripts were mapped to a total of 6692 genes. At $t_{0}$, when challenged to YPL (compared to YPD), a deregulation of 1283 genes (FDR $<0.005$ and $\mid \log _{2} \mathrm{FCl}>1$ ) was observed, being almost equally distributed among up-regulated $\left(\mathrm{N}=628 ; \log _{2} \mathrm{FC}>1\right)$, and down-regulated genes $\left(\mathrm{N}=655 ; \log _{2} \mathrm{FC}<-1\right.$; Exact binomial test: $p$-value $=0.47$; Figure 2 ). The evolved population $t_{100}$ challenged with YPL, showed 1015 deregulated genes, not being evenly distributed between up- $(\mathrm{N}=615)$ and down-regulated genes $\left(\mathrm{N}=400\right.$; Exact binomial test: $p$-value $=1.59 \times 10^{-11}$; Figure 2$)$. When comparing transcriptomic response to YPL between $t_{100}$ and $t_{0}$, only 431 of the de-regulated genes were also altered at $t_{0}$, with 243 up-regulated genes at $t_{0}$ (Figure 2). This is significantly higher than the number of down-regulated genes at both populations $\left(\mathrm{N}=138\right.$; Fisher's exact test: odds ratio $=1.83, p$-value $\left.=3.49 \times 10^{-7}\right)$. 


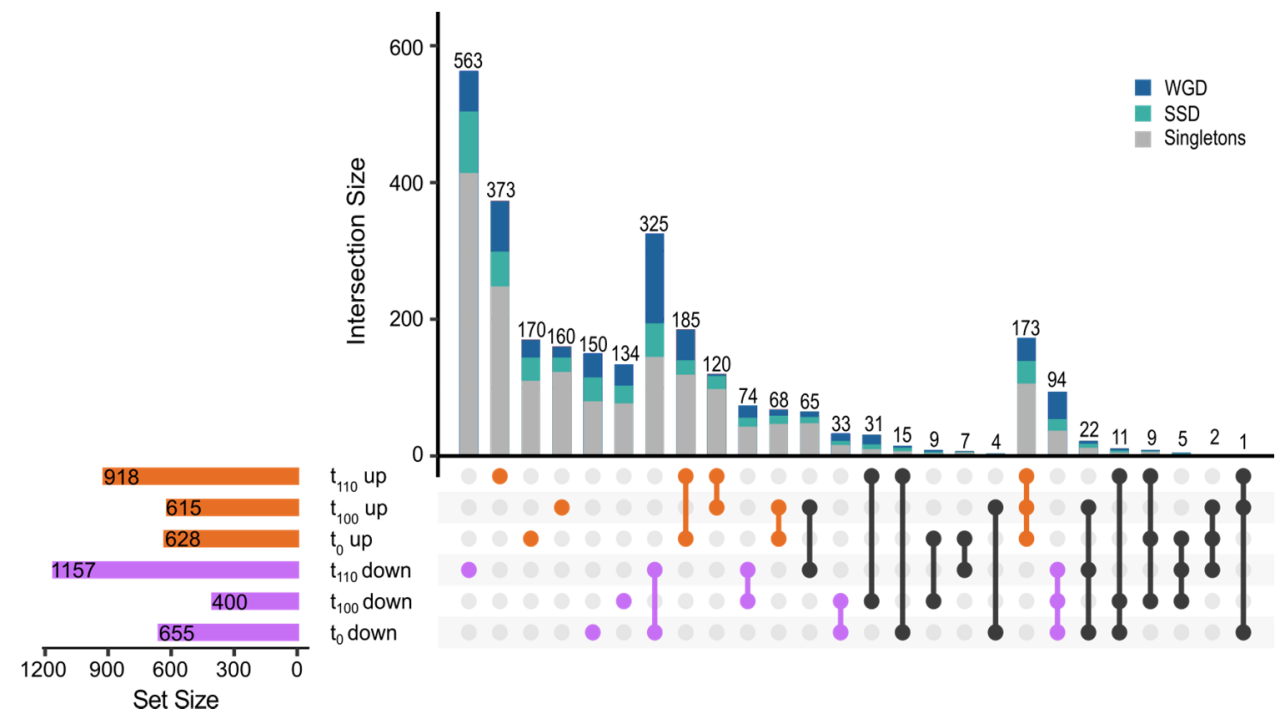

Figure 2. Comparison of de-regulated genes in response to YPL in the yeast Saccharomyces cerevisiae under diversification or adaptive experimental evolution. The UpSet graph shows the number of genes (singletons, WGDs or SSDs) in each category, shared or discordant between each data set. Up-regulated genes shown in orange, down-regulated in violet, and the discordant gene shown in black at different time-points. Graph drawn by the R package UpSetR [33].

Indeed, to point out the high reliability between the transcriptomic data obtained here, we investigated how many genes were up-regulated at $t_{100}$ but down-regulated at $t_{0}$, observing only four genes, whereas nine genes were observed in the opposite direction, being down-regulated at $t_{100}$ after being up-regulated at $t_{0}$. This indicates that in general, the regulation sense is kept under our evolutionary experiment, meaning that up-regulated genes at $\mathrm{t}_{0}$ are also up-regulated at $\mathrm{t}_{100}$ and that down-regulated genes at $\mathrm{t}_{0}$ are also down-regulated at $\mathrm{t}_{100}$ (Figure 2).

To understand which transcriptomic changes drive the adaptation process, we analysed the transcriptome of the population $\mathrm{t}_{110}$, which had been grown for 10 passages in YPL, having lactic acid/lactate as the sole carbon source. In this early adaptation, 2075 genes altered their expression profile when compared to the growth in the YPD control media, showing a huge cellular reprogramming. Contrary to what was observed in the $\mathrm{t}_{0}$ and $t_{100}$ populations, this adapted population showed 1157 down-regulated genes, being significantly higher than the number of up-regulated genes $(\mathrm{N}=918$; Exact binomial test: $p$-value $=1.69 \times 10^{-7}$ ).

Comparing the altered genes at $t_{0}, t_{100}$, and $t_{110}$, we identified a core set of 317 transcriptionally altered genes, responding to lactic acid/lactate stress (Figure 2), with 267 showing the same expression profile. More specifically, 94 genes were down-regulated and 173 genes were up-regulated at all time points. Interestingly, only 181 of the 2803 responding genes showed a different expression profile (Figure 2), 1072 genes retained the same profile and 1550 genes were profile and point specific.

\subsection{Many Cellular Processes Are Altered When S. cerevisiae Is Challenged with Lactic Acid/Lactate}

To shed light on how the yeast changed its cellular response when the environment suddenly changes the carbon source, we analysed what cellular processes were altered in the different populations according to the Gene Ontology terms (GO) using the $\mathrm{R}$ package clusterProfiler [34]. At $t_{0}$ up-regulated genes were enriched in functional categories, including "aerobic respiration", "drug metabolic process", "oxidation-reduction processes" and "ATP metabolic process", whereas fundamental cell processes were down-regulated, including "cytoplasmic translation", "ribosome biogenesis", "ribosome assembly", "rRNA metabolic process", and "RNA transport" (Figure 3). 


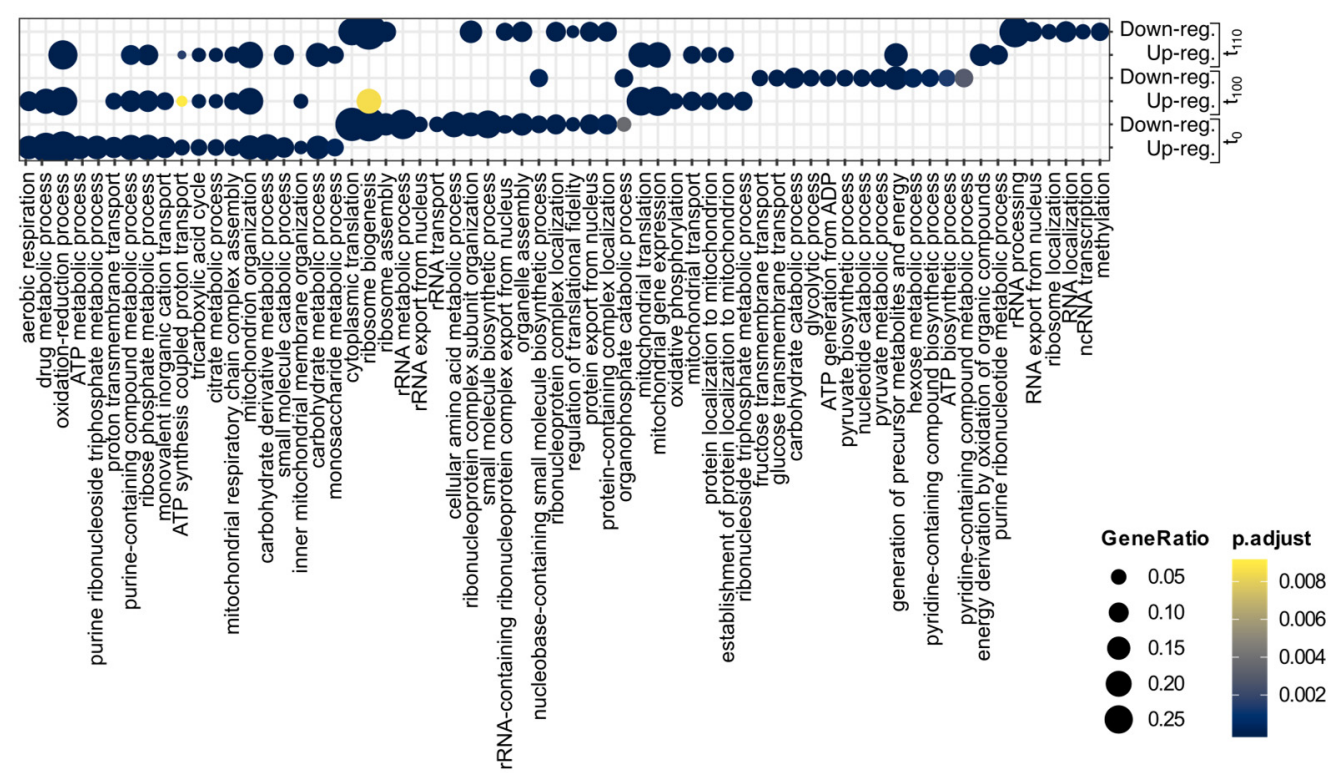

Figure 3. Gene ontology (GO) term enrichment analysis of deregulated genes in response to YPL in the yeast Saccharomyces cerevisiae under diversification or adaptive experimental evolution. GO enrichment is split for tested populations either upor down-regulated.

For the population $\mathrm{t}_{100}$, we observed a large overlap with $\mathrm{t}_{0}$ for up-regulated genes, including "aerobic respiration", "drug metabolic process" or "oxidation-reduction processes", and found some functional groups related to mitochondria as "mitochondrial translation", "mitochondrial gene expression" and "oxidative phosphorylation" that were down-regulated in $t_{0}$ (Figure 3), whereas $t_{100}$ down-regulated gene GO enrichment included "organophosphate catabolic process", "fructose transmembrane transport", "glucose transmembrane transport", and "carbohydrate catabolic process" that were almost exclusive for this time point (Figure 3).

In the population $t_{110}$, up-regulated genes were enriched for many cellular processes shared with populations, $\mathrm{t}_{0}$ and $\mathrm{t}_{100}$, like "oxidation-reduction process", "purine-containing compound metabolic process" or "mitochondrion organization"; having three specific functional categories: "energy derivation by oxidation of organic compounds", "generation of precursor metabolites and energy" and "purine ribonucleotide metabolic process" (Figure 3), whereas down-regulated gene enrichment was partially shared with $\mathrm{t}_{0}$, including "cytoplasmic translation", ribosome biogenesis" or "ribosome assembly"; also showing a specific signature that included "rRNA processing", "RNA export from nucleus", and "ribosome localization" (Figure 3).

\subsection{The Implication of Duplicated Genes in the Transcriptional Response of S. cerevisiae to Lactic} Acid/Lactate

As indicated previously, the budding yeast keep around a third of its genome in duplicate, as a result of the ancestral whole-genome duplication, genome rearrangement and reduction, and coetaneous small-scale duplication events that took place 100 MYA. Thus, these ancestral duplicates can be studied depending on the molecular mechanism they originate from, being divided into WGDs (whole-genome duplicates) and SSDs (small scale duplicates) $[5,6,21,22,35]$. For this study, we used a starting set of 1101 duplicated pairs split into 548 WGD and 553 SSD pairs, to analyse their contribution to the transcriptional and cellular response observed to lactic acid/lactate as the sole carbon source. Of this data set, we were able to identify expression data from 1094 WGDs and 1097 SSDs with a differential response at each time point (Figure 4A). 

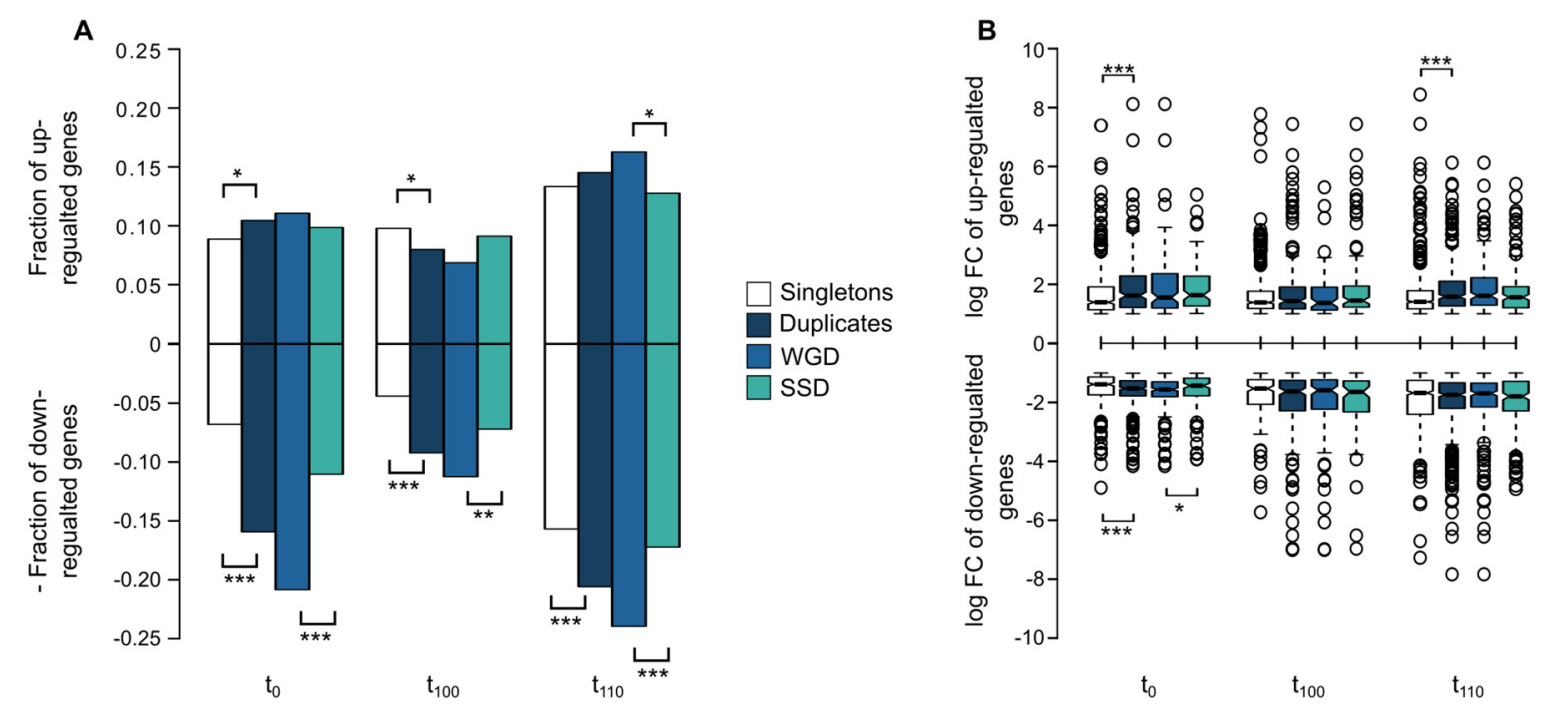

Figure 4. Transcriptional response to lactic acid/lactate in comparison to the response to glucose as the sole carbon source. (A) Distribution of fractions of deregulated genes, depending on their classification as singletons or duplicates, and within duplicates, depending on their origin, WGDs (whole-genome duplicates) or SSDs (small-scale duplicates); (B) Distribution of expression level as the logarithm of fold-change $\left(\log _{2} \mathrm{FC}\right)$ for singletons and duplicates, with duplicates also being divided into WGDs and SSDs. Statistical differences among means were determined with *** or ***, corresponding to the probabilities $p<0.05, p<0.005$, and $p<0.001$, respectively, using a Wilcoxon rank test.

For the population $\mathrm{t}_{0}$, of the 1283 deregulated genes 578 were duplicated genes, observing a significantly larger fraction than expected (Exact binomial test: $p$-value $<2.2 \times 10^{-16}$ ). Considering the distribution of those duplicates between the mechanisms that give rise, WGD or SSD, we observed that WGDs $(\mathrm{N}=349)$ contribute significantly to the transcriptional response than expected by chance (exact binomial test: $p$-value $=5.48 \times 10^{-7}$ ), whereas SSDs $(\mathrm{N}=229)$ did not (Figure $4 \mathrm{~A})$. Out of the up-regulated 229 duplicates, we observed no statistical difference between the duplication method, WGDs $(\mathrm{N}=121)$ and SSDs $(\mathrm{N}=108$; Fisher's exact test: odds ratio $\mathrm{F}=1.123, p$-value $=0.406)$. Whereas when considering down-regulated duplicates, we observed roughly double as many WGDs $(\mathrm{N}=228)$ compared to SSDs $\left(\mathrm{N}=121\right.$; Fisher's exact test: odds ratio $\mathrm{F}=1.889, p$-value $=9.65 \times 10^{-8}$; Figure $4 \mathrm{~A}$ ).

For the evolved population $\mathrm{t}_{100}, 377$ of all deregulated genes were duplicates, a proportion higher than expected by chance (Exact binomial test: $p$-value $=3.23 \times 10^{-3}$ ), as observed in $\mathrm{t}_{0}$, with equal contribution of WGDs $(\mathrm{N}=198)$ and SSDs $(\mathrm{N}=179$; Exact binomial test: $p$-value $=0.328$ ). However, in contradiction to what was observed at $\mathrm{t}_{0}$, the deregulated duplicates were not equally distributed between up-regulated $(\mathrm{N}=175)$ and downregulated duplicates $\left(\mathrm{N}=202\right.$; Fisher's exact test: odds ratio $=1.542, p$-value $\left.=2.383 \times 10^{-6}\right)$. Analysing the distribution of WGDs and SSDs for up- and down-regulated genes, we observed significantly more down-regulated WGDs than SSDs $\left(\mathrm{N}_{\mathrm{WGDs}}=123, \mathrm{~N}_{\mathrm{SSDs}}=79\right.$; Fisher's exact test: odds ratio $=1.63, p$-value $\left.=1.13 \times 10^{-3}\right)$, with no difference observed between the two duplication methods in up-regulated genes $\left(\mathrm{N}_{\mathrm{WGDs}}=75, \mathrm{~N}_{\mathrm{SSDs}}=100\right.$; Fisher's exact test: odds ratio $=0.734, p$-value $=0.0584$; Figure $4 \mathrm{~A}$ ).

For the population, $\mathrm{t}_{110}$ adapted to lactic acid/lactate, 769 of the duplicated genes altered their expression, being significantly higher than expected (Exact binomial test: $p$ value $=3.428 \times 10^{-5}$ ), with the greatest contribution coming from the WGDs $\left(\mathrm{N}_{\mathrm{WGD}}=440\right.$, $\mathrm{N}_{\mathrm{SSD}}=329$; Exact binomial test: $p$-value $=7.09 \times 10^{-5}$ ). As observed in both $\mathrm{t}_{0}$ and $\mathrm{t}_{100}$, we again had a higher proportion of duplicated genes being down-regulated $(\mathrm{N}=451) \mathrm{com}-$ pared to singletons $\left(\mathrm{N}=706\right.$; Fisher's exact test: Odds ratio $=1.312, p$-value $\left.=3.92 \times 10^{-5}\right)$. Furthermore, WGDs $(\mathrm{N}=262)$ were again overrepresented in the down-regulated duplicates compared to SSDs $\left(\mathrm{N}=189\right.$; Fisher's exact test: odds ratio $\mathrm{F}=1.390$-value $\left.=1.16 \times 10^{-3}\right)$. 
This trend was also observed in up-regulated $\left(\mathrm{N}_{\mathrm{WGD}}=178, \mathrm{~N}_{\mathrm{SSD}}=140\right.$; Fisher's exact test: odds ratio $\mathrm{F}=1.27, p$-value $=0.0476$; Figure $4 \mathrm{~A}$ ).

Previously we determined that expression level (fold-change, FC) also contribute to duplicates preservation and to their functional innovation through response to different stresses [24]. In this case, we observed at $t_{0}$ that duplicated genes exhibited a higher absolute log fold-change $($ median $=1.536)$ than singletons $($ median $=1.388$; Wilcoxon test: $p$-value $=4.58 \times 10^{-7}$ ) of the de-regulated genes. Furthermore, this was also the case when separating out into up- and down-regulated genes (Figure 4B). Considering the origin of those duplicates, down-regulated WGDs (median $=-1.561$ ) were more down-regulated than SSDs (median $=-1.431$; Wilcox test: $p$-value $=0.045$; Figure $4 \mathrm{~B}$ ) whereas no differences among duplicate types were observed in up-regulated genes $\left(\right.$ median $_{\mathrm{WGD}}=1.549$, median $_{S S D}=1.631$; Wilcox test: $p$-value $=0.818$ ). At population $t_{100}$ we did not observe any difference between expression levels of altered genes, regardless of the comparison carried out (Figure $4 \mathrm{~B}$ ). Whereas at population $\mathrm{t}_{110}$, one significant difference with up-regulated duplicates showed a significantly higher expression fold-change (median $=1.658$ ) than singletons (median $=1.538$; Wilcoxon test: $p$-value $=2.448 \times 10^{-4}$ ), with no difference detected for this time-point (Figure 4B).

\subsection{The Cellular Re-Programming in Response to Lactic Acid/Lactate Is Driven through Duplicated Genes}

We identified the duplicated genes that were altered at the core gene set, hence those that were altered in all populations $\left(\mathrm{t}_{0}, \mathrm{t}_{100}\right.$, and $\left.\mathrm{t}_{110}\right)$. We found that 148 duplicated genes belong to the core category, with 124 having the same expression profile at all three populations $\left(\mathrm{N}_{\mathrm{up}}=67\right.$ and $\left.\mathrm{N}_{\text {down }}=57\right)$. This core set gene showed enrichment of down-regulated duplicates (Fisher's exact test: odds rate $\mathrm{F}=3.164, p$-value $=5.0 \times 10^{-8}$; Figure 2) but the up-regulated genes were distributed among duplicates and singletons as would be expected (Fisher's exact test: odds rate $\mathrm{F}=1.298, p$-value $=0.1015$ ). When investigating what functional categories were affected, we observed that altered core genes were enriched mainly for functions involved in precursor metabolites and energy, such as "oxidation-reduction process", "generation of precursor metabolites and energy", "aerobic respiration" and "mitochondrial respiratory chain complex assembly".

2.6. Chaperones, Heat Shock Proteins and Stress-Related Proteins Responding to Lactic Acid/Lactate as Carbon Source

Among the lactate quick response genes (those up-regulated at $t_{0}$ and $t_{100}$ ) we found: Gre1 (YPL223C) a WGDs responsive to stress; Fyv5 (YCL058C) a gene de novo originated from non-coding sequence involved in ion homeostasis and required for survival after exposure to killer toxins; and Fyv4 (YHR059W) a protein of unknown function also required for survival to killer toxins.

Among the highly expressed genes responding to acute lactate exposure (Lat 110 population) we found several heat shock proteins: Hsp26 (YBR072W; SSD), Hsp30 (YCR021C), Hsp42 (YDR171W), Hsp78 (YDR258C), Hsp82 (YPL240C; WGD) Sse2 (YBR169C), Ssa4 (YER135C), Hsp104 (YLL026W; SSD), Ssc1 (YJR045C, HSP70 family ATPase, WGD); chaperone Apj1 (YNL077W; SSD); co-chaperones Mdj1 (YFL088W) and Sis1 (YNL007C), all involved in protein folding/refolding under heat-shock and stressing conditions (including lactic acidosis of the environment), some of them with implications on DNA replication stress. Other proteins involved in DNA replication stress, oxidative stress or stressresponse elements were Ctr1 (YPR124W), Gph3 (YPR160W), Gsy2 (YLR258W; WGD), Tma10 (YLR327C; WGD), Pgm2 (YMR105C; WGD), Opi10 (YOL032W), Gad1 (YMR250W; SSD), Fes1 (YBR101C), Rgi (YER067W; WGD), Btn2 (YGR142W; WGD), Rie1 (YGR250C), Tdh1 (YJL052W), Roq1 (YJL144W) and Mrs4 (YKR052C; WGD). 


\subsection{Metabolic Evolution of YPL Adapted S. cerevisiae Populations}

To determine similarities among the different populations after the experimental evolution, we measured the metabolic distance among the three populations, this being the grade of sharing of cellular GO processes to determine proximity of the populations in terms of metabolism (see Materials and Methods section). The metabolic distance (MD) was determined for all the transcriptionally altered genes (including duplicates and singletons), as well as for the up- and down-regulated genes between pairs of the $t_{0}, t_{100}$, and $t_{110}$ populations. As expected, we observed that the most related metabolic distance of the populations for the whole altered gene set were $t_{0}$ and $t_{100}$ since the population $t_{100}$ was neutrally evolved from the population $t_{0}$ to increase its genetic variability. The same was true for the up-regulated gene set but surprisingly not for the down-regulated gene (Table 1). When we analysed only the duplicated genes, we observed that the closest metabolic distance for all comparisons was between $\mathrm{t}_{0}$ and $\mathrm{t}_{110}$ populations.

Table 1. Metabolic distances between evolved populations in response to lactic acid/lactate as sole carbon source.

\begin{tabular}{cccccccccc}
\hline & & Altered & & \multicolumn{3}{c}{ Up-Regulated } & \multicolumn{3}{c}{ Down-Regulated } \\
$\mathbf{t}_{\mathbf{0}}-\mathbf{t}_{\mathbf{1 1 0}}$ & $\mathbf{t}_{\mathbf{1 0 0}}-\mathbf{t}_{\mathbf{1 1 0}}$ & $\mathbf{t}_{\mathbf{0}}-\mathbf{t}_{\mathbf{1 0 0}}$ & $\mathbf{t}_{\mathbf{1 1 0}}$ & $\mathbf{t}_{\mathbf{1 0 0}}-\mathbf{t}_{\mathbf{1 1 0}}$ & $\mathbf{t}_{\mathbf{0}}-\mathbf{t}_{\mathbf{1 0 0}}$ & $\mathbf{t}_{\mathbf{0}}-\mathbf{t}_{\mathbf{1 1 0}}$ & $\mathbf{t}_{\mathbf{1 0 0}}-\mathbf{t}_{\mathbf{1 1 0}}$ \\
\hline All & 0.1914 & 0.3713 & 0.5359 & 0.3295 & 0.2897 & 0.2890 & 0.6082 & 0.4021 \\
Singletons & 0.3302 & 0.5934 & 0.3585 & 0.3028 & 0.2611 & 0.1549 & 0.5000 & 0.4789 \\
Duplicates & 0.4955 & 0.1279 & 0.8488 & 0.2466 & 0.4028 & 0.5694 & 0.9048 & 0.1684 \\
WGDs & 0.3962 & 0.0132 & 0.9623 & 0.0667 & 0.5652 & 0.6522 & 0.8750 & 0.0435 \\
$\quad$ SSDs & 0.4815 & 0.7692 & 0.7037 & 0.5641 & 0.5455 & 0.3636 & 0.8667 & 0.5111 & 0.9365 \\
\hline
\end{tabular}

\section{Discussion}

Yeast, like many other organisms, uses glucose as the main carbon source to obtain energy, and is able to modify its metabolism depending on the available carbon sources. The budding yeast undergoes fermentative metabolism of glucose to obtain ATP and other basic metabolic precursors from the complex YPD medium (containing $2 \%$ dextrose) having ethanol, glycerol, and lactate/lactic acid as the main by-products. These by-products can become potent control molecules that limit the development of other microorganisms by exerting different kinds of stresses or are used as alternative carbon sources to obtain energy through respiration. In this work, we determine the contribution of duplicated genes in response to the carbon source switch from glucose to lactic acid/lactate and how this transcriptional switch affected yeast growth.

\subsection{Lactic Acid as Non-Fermentable Carbon Source Affects S. cerevisiae Growth Parameters}

Lactic acid, an organic acid produced by some yeasts and lactic bacteria through sugar media fermentation, is usually produced as its conjugated anion lactate due to intracellular $\mathrm{pH}(\mathrm{pKa}=3.68)$. This weak organic acid compound has a wide range of industrial applications ranging from food preservation to pharmaceutical production to plastic production. Moreover, it is a biological stressor, by either forcing a growth arrest and a metabolic rewire of the target organism due to the lack of glucose in the medium or by acidic stress induced by the dissipation of $\mathrm{pH}$ gradient through the plasma membrane $[28,36]$. In addition, lactate has been recently classified as a signaling molecule in several human diseases, including cancer, deserving further research on its metabolism and transcriptional effects [37-40].

The presence of this weak acid in the culture media (either in small or at factory scales) induces in a first step a cell-cycle arrest, resuming cell growth after several hours. This transient growth arrest is lost when cells are pre-adapted to weak acids, such as lactic acid or acetic acid, implying a durable transcriptomic rewire [41]. In our work, we saw this growth arrest with a significant decrease of growth rate when switching carbon source from glucose to lactic acid, this decrease was also observed in the lactic acid short-adapted lines (population YPL $t_{110}$, Figure 1B). However, as indicated, cells are able to resume 
cell growth after several hours, time allocated to transcriptional activity, and cell growth and reproduction, which at the end indicates an increase of the carrying capacity of the culture. Similarly, our YPL-adapted lines showed a significant increase of carrying capacity compared to the non-adapted ones (control lines), indicating successful growth resumption (see Figure 1C and Supplementary Materials Figure S1B). In other works, we demonstrated that this short adaptive experimental evolution (only 33 generations) also affected growth rate, with a significant reduction when challenged to glucose-deprived media using other non-fermentative carbon sources [26,27]. However, when using glycerol or ethanol as nonfermentative carbon sources, growth was resumed without a significant increase of biomass as observed with lactic acid/lactate (Figure 1C and Supplementary Materials Figure S1B). These results would indicate that in this case, we are not yet fixing adaptive mutations, as expected if a genotypic switch took place after the adaptive process [42-49]. But the increase of carrying capacity in the YPL adapted lines is also in agreement with an increase of TCA fluxes, as explained in [50]. Indeed, we observed phenotypic heterogeneity in the evolved cells, which decreased after adaptive evolution (see Figure 1, and Supplementary Materials Figure S1). It seems that our populations show heterogeneous phenotypes linked to transcription heterogeneity in lactic acid/lactate medium, as observed previously to adaptation to other functional trade-offs [51,52].

\subsection{Lactic Acid as a Non-Fermentable Carbon Source Affects S. cerevisiae Transcriptomic Response}

The improvement of lactic acid production from sugar fermentation in S. cerevisiae has been achieved by alcohol fermentation inhibition, by increasing methyltransferases, and by modulation of Jen1 and Ady2 monocarboxylic permeases [53-55]. These two transporters (repressed by glucose) mediate the export of acetate, formate, propionate, and lactate from the cytoplasm reducing the internal acidic stress and increasing the release of lactic acid. However, these two transporters also work in the reverse direction, being involved in the use of lactic acid/lactate as a carbon source by the budding yeast [54]. In this work, we forced the cell to use lactic acid/lactate as the sole carbon source, finding that both transporters Jen 1 and Ady2 were overexpressed since the first challenge, and that ethanol reduction to acetaldehyde was also increased, redirecting the central metabolism to obtain energy (see Figure 5).

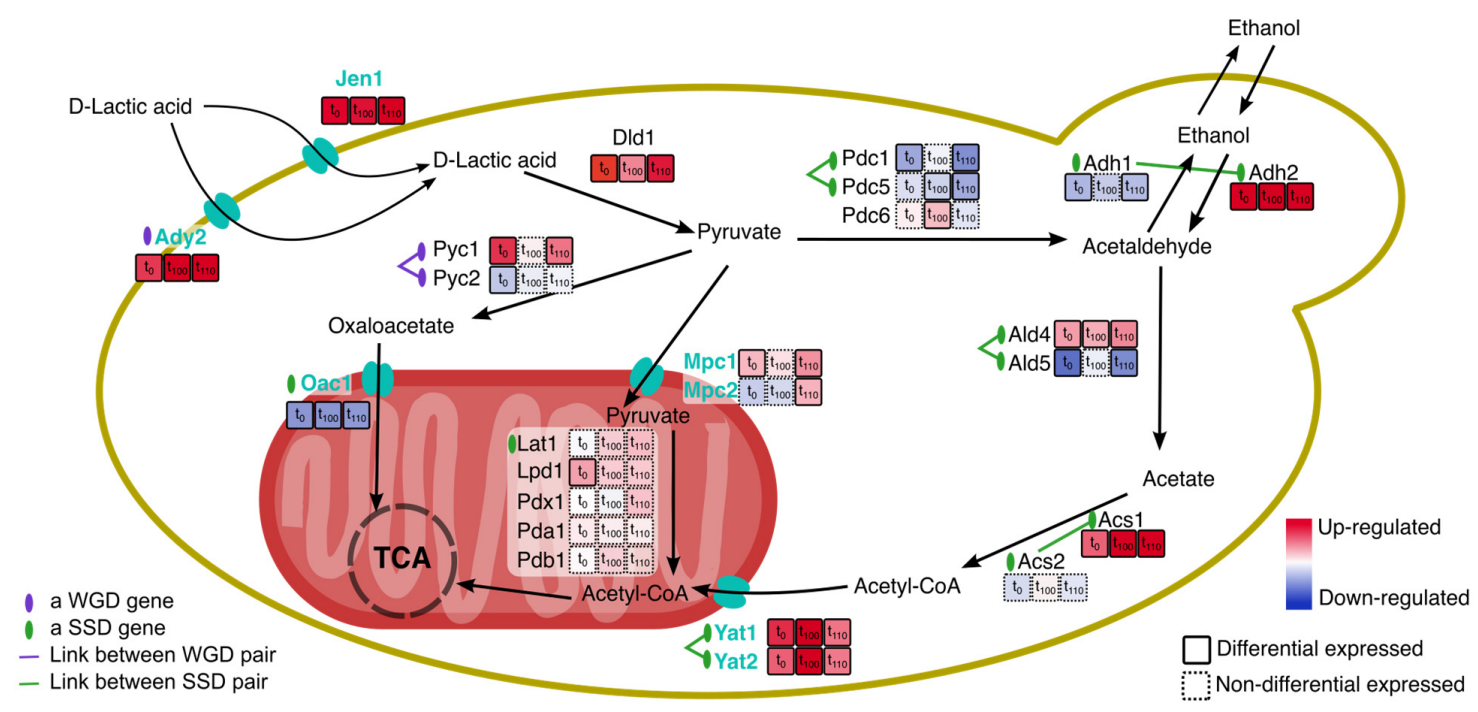

Figure 5. Saccharomyces cerevisiae Y06240 lactic acid/lactate uptake mechanism, with the indication of metabolic, rewire after experimental evolution on YPL. Lactate transporters both in periplasmic and mitochondrial membranes have been indicated in green. Some of the duplicated genes implicated in this lactate uptake and metabolism have been indicated with colors, whereas singletons are in black. Expression level (up in red and down-regulated in blue) and statistical significance (differentially expressed genes in a continuous line, and non-differentially expressed genes in dashed line) of each gene are indicated. 
It has been demonstrated that under glucose limiting conditions, the budding yeast undergoes a significant transcriptional switch, with a fast response under an acute situation or with a slow response under chronic glucose limitation [56,57]. As indicated previously, the budding yeast can use several non-fermentable carbon sources that are also products of glucose metabolism, such as ethanol, glycerol, acetate, and lactate, inducing a transcriptional regulation involving overexpression of membrane transporters and activation of transcription factors for the use of these non-fermentable carbon sources [58,59]. In this work, we show that the complete replacement of glucose (dextrose) by a non-fermentable carbon source such as lactic acid/lactate in the growing medium (from YPD to YPL) drives to a complete transcriptomic re-wiring affecting central metabolism genes that would affect growing parameters (see Figures 3 and 5).

Similarly, when the hybrid yeast Zygosaccharomyces parabailii was subjected to lactic acid supplementation with a medium rich in glucose $(4 \%)$, a transcriptomic rewire was observed [60]. This species shows a weak acid stress tolerance by modulating cell wallrelated genes, including the transcription factors Haa1, Aft1/Aft2 (repression of these genes to avoid lactic acid uptake), by the induction of genes involved in oxidative stress response and iron homeostasis, and by amplification by gene duplication at a small scale of formate dehydrogenase (FDH) genes, identifying such SSDs directly linked to lactic acid tolerance with differential gene expression between copies [60]. The budding yeast, S. cerevisiae, undergoes a different strategy (when tested under acidic stress in the presence of glucose), inducing ROS response, affecting iron homeostasis, and expending large amounts of ATP through Pdr12 ABC transporter (YPL058C) that catalyses lactic acid [41]. In our case, we observed that under media with no glucose, the budding yeast forces the entry of lactate with over-expression of transporters Jen1 and Ady2, and re-wires the central metabolism to the production of energy via pyruvate and acetate synthesis from lactate through up-regulation of a set of duplicated genes, including some related to ROS response and heat-shock family proteins (see some of the duplicates in Figure 5).

Among the responding genes to lactate in the core set (altered genes shared by all three populations), we found Idp2 (YLR174W; WGD), Cyb2 (YML054C; singleton), Mls1 (YNL117W; SSD), Acs1 (YAL054C; SSD), and Rgi2 (YIL057C; WGD) genes implied in the utilization of non-fermentable carbon sources, with affected growth parameters even under vegetative growth and decreased lifespan [58,59].

\subsection{Ancient Duplicates Direct the Transcriptomic Response}

As indicated previously, gene duplication is a major force in evolution, sourcing new genetic material and novel functions, being related to the radiation of angiosperms and developmental complexity in animals [61-65]. In this study, we were interested in deciphering the role of the anciently duplicated genes during the adaptation to a challenging environment, the YPL medium containing lactic acid/lactate as the sole carbon source, by analysing results of an adaptive laboratory experiment.

Experimental evolution has been a common tool in the past years to achieve insight into molecular mechanisms and cellular responses underlying adaptation [66-68]. As shown, we found that (Figures 2 and 4) duplicates direct the transcriptomic response to an acidic environment with lactic acid/lactate as the sole carbon source after experimental evolution. Duplicates significantly alter their expression profile compared to singletons, showing also significantly higher expression fold-change than singletons (Figure 4). When studying the transcriptional response, a core set of genes was identified, with an enrichment of the WGDs. Whole-genome duplicates implied in glycolysis, glucose metabolism, and hexose catabolic process were repressed. We also observed down regulation of Sam2 (YDR502C) involved in direct lactic acid tolerance and production [54]. Up-regulated WGDs were involved in "oxidation-reduction process", "generation of precursor metabolites and energy", "aerobic respiration" and "mitochondrial respiratory chain complex assembly" (Figure 3). Of these pairs, we also observed a discordant trend (discordant category as in $[23,24]$ ) with opposite transcriptional response to duplicated pairs, including SSD pairs 
such as Acs1/Acs2, Ald4/Ald5, and Adh1/Adh2, and the WGD pair Pyc1/Pyc2 (Figure 5), and only one SSD gene pair, Yat1/Yat2, was up-regulated.

\subsection{Lactic Acid/Lactate as the Sole Carbon Source Induces More Than a Single Stress Response}

Wild-type yeasts can grow at $\mathrm{pH}$ values ranging from 2.5 to 8.5 , with growth and fermentation kinetics not affected between $\mathrm{pH} 3.5$ and 6.0. As indicated previously, lactic acid/lactate is purely a respiratory substrate for Saccharomyces cerevisiae that affects growth parameters by reducing growth rate and increasing biomass production. This lactate consumption increases the $\mathrm{pH}$ of the medium by decreasing the basal respiratory rate, mainly due to a decrease in ATP consumption linked to the maintenance of intracellular $\mathrm{pH}$ and reduction of the number of mitochondria per cell [69]. The intracellular $\mathrm{pH}$ is also a tightly controlled factor, with great differences among cell compartments (vacuole, mitochondria, nucleus, Golgi network, peroxisomes, and secretory vesicles), that alters the cellular set-up and cell physiology affecting multiple regulatory levels simultaneously [31,70]. A decrease of the internal $\mathrm{pH}$ will affect enzymes activity, and also by changing interaction between residues of amino acid side chains conformational stability of proteins and interactions between proteins will be affected. In addition, oxidation-reduction potential (transference of electrons and expenditure of NADPH) is also dependent on internal $\mathrm{pH}$, affecting ROS response-related proteins (reviewed in [70]). Moreover, acidification of cytosol will affect other structural molecules as lipids or coupled phosphates affecting intracellular compartment membranes and DNA (reviewed in [70] and references within). Each of these steps seems to be involved in the induction of acidic, oxidative, and DNA damage stresses, which were observed in this work (see Figure 3). In addition, the conformational instability of proteins might be responsible for the observed up-regulation of a long list of heat shock proteins, chaperones, and co-chaperonins (see Section 2.6). This deserves further study to determine their implication on system robustness, as this response was only observed after chronic exposure to lactic acid/lactate. The implication of altered duplicates on such responses (to different stresses) still deserves further research, but some light has been shed on how duplicates were selected, preserved, and still able to innovate following Ohno's dilemma [71,72].

\section{Materials and Methods}

\subsection{Yeast Strain, Culture and Adaptive Experimental Evolution}

The yeast Saccharomyces cerevisiae strain Y06240, a derivative of BY4741 with msh2 gene deleted from the YKO collection (Mata; his3D1; leud2D0; met15D0; ura3D0; msh2::kanMX4), was used [21]. As previously described, a homogeneous population $\left(\mathrm{t}_{0}\right)$ was founded by growing a single colony into $5 \mathrm{~mL}$ of YPD $(2 \%(w / v)$ bactopeptone, $1 \%(w / v)$ yeast extract, $2 \%(w / v)$ dextrose; supplemented with $100 \mu \mathrm{g} / \mathrm{mL}$ kanamycin) for $24 \mathrm{~h}$ at $28{ }^{\circ} \mathrm{C}$ and $220 \mathrm{rpm}$, and evolved through $1 \%$ daily bottlenecks (by transferring $50 \mu \mathrm{L}$ of culture into $5.0 \mathrm{~mL}$ of fresh YPD medium; 6.6 generations per passage) for 100 passages ( $\mathrm{t}_{100} ; \sim 660$ generations) $[26,27]$. From passage $100\left(\mathrm{t}_{100}\right)$, one population (a1) was selected and divided into two sets, a control set adapted to YPD (Da set), and the one challenged to YPL (La set), medium containing 3\% lactic acid as sole carbon source (YPL: 3\% $(v / v)$ lactic acid, $2 \%(w / v)$ bactopeptone, $1 \%(w / v)$ yeast extract, $\mathrm{pH} 5.5$; supplemented with $100 \mu \mathrm{g} / \mathrm{mL}$ kanamycin). Each set consisted of three biological replicates, being subjected to daily passages, with $10 \%$ population bottleneck (by transferring $500 \mu \mathrm{L}$ of culture into $5.0 \mathrm{~mL}$ of fresh YPD or YPL media) for another 10 passages ( 3.3 generations per passage). During the evolution, a fossil record was constructed, with glycerol stock of populations every 10 passages in the diversification experimental evolution or every 5 passages in the adaptive evolution, being preserved at $-80^{\circ} \mathrm{C}$ (Figure 1A).

\subsection{Growth Characterization under Lactic Acid Use as Sole Carbon Source}

Evolved yeasts at $t_{0}, t_{100}$, and $t_{110}$ were characterized for growing ability response to carbon source, either in ancestral medium (YPD) or challenged to YPL (Figure 1A). Cells 
from fossil records were recovered in the corresponding growing media, by seeding 5 to $50 \mu \mathrm{L}$ of glycerol stock into $5.0 \mathrm{~mL}$ of fresh medium in $50 \mathrm{~mL}$ conic vials. After $24 \mathrm{~h}$ at $28^{\circ} \mathrm{C}$ and $200 \mathrm{rpm}$, cells were diluted till $\mathrm{OD}_{600} \sim 0.1$ in $200 \mu \mathrm{L}$ volume and growth was recorded in a Bioscreen c MBR plate reader system (Oy Growth Curves Ab Ldt., Helsinki, Finland) taking $\mathrm{OD}_{600}$ measurement every $15 \mathrm{~min}$, with brown filter and continuous shaking at $28^{\circ} \mathrm{C}$. Each line and time points were challenged in both YPD and YPL with at least 5 technical replicates.

Growth rate $(\mathrm{r})$ and carrying capacity $(\mathrm{k})$ were determined from the logistic adjustment of corrected $\mathrm{OD}_{600}$ time data series in each well with Growthcurver package in $\mathrm{R}$ [32]. Means were compared among treatments and lines with Wilcoxon rank test in R [73].

\subsection{RNAseq and Transcriptomic Profiling}

Evolved yeasts at $t_{0}, t_{100}$, and $t_{110}$ were characterized for their transcriptional response to carbon source switch or their adaptation to this acidic environment (Figure 1). As described previously, cells from fossil records were recovered in the corresponding growing media, and after reaching $\mathrm{OD}_{600} \sim 0.6\left(\sim 16 \mathrm{~h}\right.$ at $28{ }^{\circ} \mathrm{C}$ and $\left.200 \mathrm{rpm}\right)$, challenged to YPD and YPL, in triplicate. Cultures were stopped at $\mathrm{OD}_{600} \sim 0.6$ (by placing them in an ice bath), cells harvested by centrifugation and total RNA extracted using RNEasy kit (Qiagen) following manufacturer instructions. RNA quality was checked with QuBit 4, and those samples with RIN $>8$ were used for library construction.

Stranded RNA libraries were constructed using TruSeq stranded mRNA (Illumina) from oligo-dT captured mRNAs. Libraries were run in NextSeq 500 (Illumina) at $75 \mathrm{nt}$ single read by using the High Output 75 cycles kit v2.0 (Illumina). RNA libraries were constructed and sequenced at Genomic core facility at Servicio Central de Soporte a la Investigacion Experimental (SCSIE) from University of Valencia, Spain. Raw reads were deposited at SRA NCBI database with accession numbers PRJNA321113 $\left(\mathrm{t}_{0}\right.$ in YPD and

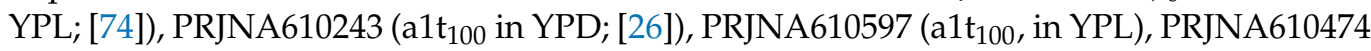
(Da1t 110 , in YPD; [26]) and PRJNA610717 (La1t 110 , in YPL). Each accession number contains three libraries corresponding to the technical replicates.

Raw reads were analysed using FastQC report, cleaned with CutAdapt, and trimmed for quality and length (Pred score inferior to 20 and size less than $40 \mathrm{nt}$ were discarded). Reads were aligned with Bowtie2 (up to two mismatches accepted) to the reference S288c strain genome (only CDS; assembly R64) [26]. Statistical assessment of differential gene expression was carried out with edgeR, setting false discovery rate (FDR) at $<0.005$, and applying BY correction for $p$-value (0.005) [75]. Comparisons were conducted between time points and media, taking into account the original transcriptomic background.

4.4. Identification of Duplicated Genes Involved in the Usage of Lactic Acid as Sole Carbon Source and Their Response to Acidic Stress

Differentially transcribed genes were further analysed as singletons and duplicates (homologs), duplicates were split into two, according to their mechanism of origin (WGDs or SSDs). Whole-genome duplicates (WGDs; 555 pairs) were extracted from the reconciled YGOB list v.7 (Yeast Gene Order Browser version 7 (August 2012); http:/ / wolfe.gen.tcd.ie/ /ygob; [76]), while small-scale duplicates (SSDs; 560 pairs) were identified by previously carried out best reciprocal blast searches $[21,22,26]$.

After classification of differentially expressed genes as singletons or duplicates (WGDs or SSDs), an enrichment analysis of gene ontology (GO) terms was performed using the $\mathrm{R}$ package cluster Profiler and $p$-value cut-off of $<0.01$ [34], to determine the contribution of each set in the transcriptomic response to acidic stress.

\subsection{Metabolic Distance between Populations}

The metabolic distance was calculated as previously described [27]. Briefly, lists of GO process terms enriched for transcriptionally altered genes between two populations ( $i$ and $j$ ) were compared by calculating the number of shared process terms (SP $i j)$, and the 
number of enriched terms for transcriptionally altered genes only in one of the populations but not in the other $(\mathrm{P} i$ and $\mathrm{P} j$ ), with metabolic distance (MDij) calculated as:

$$
\mathrm{MD} i j=1-(\mathrm{SP} i j / \mathrm{Min}[\mathrm{P} i, \mathrm{P} j])
$$

where $\operatorname{Min}[\mathrm{P} i, \mathrm{P} j]$ is the number of cellular processes enriched for transcriptionally altered genes for the population with the minimum number of such processes. Metabolic distance varies between 0 and 1 , with smaller values indicating the closeness of populations, and a value of 1 corresponding to two complete divergent populations, as there is no overlap in the enriched process terms shared.

\section{Conclusions}

Lactic acid/lactate is an alternative non-fermentative carbon source that also induces acidic stress to yeast cells. These cells undergo cell growth arrest, with a significant reduction of growth rate, to adjust their transcription profiling. After this transcriptional rewiring, cell growth arrest is resumed thereby producing an increase of biomass (measured as carrying capacity), even after a short-term adaptive process (33 generations). The transcriptional rewire of central metabolism includes down-regulation of WGDs implied in glycolysis, and up-regulation of several WGDs and SSDs involved in transcription adjustment, in the oxidative stress response and showing the implication of several heat shock proteins and chaperones. With this work, we add a further step in determining duplicated genes' central role in acute and chronic response to stress, ultimately with their continued involvement in the adaptation process.

Supplementary Materials: The following are available online at https:/ / www.mdpi.com/article/10 .3390/ijms222212293/s1.

Author Contributions: Conceptualization, M.A.F., C.T. and B.S.-M.; methodology, F.M., C.T. and B.S.-M.; software, C.T.; validation, C.T. and B.S.-M.; formal analysis, C.T. and B.S.-M.; investigation, F.M., C.T. and B.S.-M.; resources, C.T. and B.S.-M.; data curation, C.T. and B.S.-M.; writing-original draft preparation, F.M., C.T. and B.S.-M.; writing-review and editing, C.T. and B.S.-M.; visualization, C.T. and B.S.-M.; supervision, C.T. and B.S.-M.; project administration, C.T. and B.S.-M.; funding acquisition, M.A.F. and C.T. All authors (except M.A.F. due to unforeseen circumstances, posthumous author) have read and agreed to the published version of the manuscript.

Funding: This research was funded by Spanish National Plan for Scientific and Technical Research and Innovation from the Spanish Ministry of Economy and Competitiveness (MINECOFEDER), actually the Ministry of Science and Innovation (MCIN), Spanish Research Agency (AEI), MCIN/AEI/10.13039/501100011033 and ERDF A way of making Europe (FEDER “Una forma de hacer Europa") with grant number BFU2015-66073-P (to M.A.F.) and Generalitat Valenciana, Conselleria de Innovacion, Universidades y Sociedad Digital with grant number SEJI/2018/046 (to C.T.). F.M. was supported by a Spanish PhD Fellowship number FPI BES-2016-076677, from MCIN/AEI/10.13039/501100011033 and ESF "Investing in your future".

Institutional Review Board Statement: Not applicable.

Informed Consent Statement: Not applicable.

Data Availability Statement: Raw reads (fastq files) are available from the Sequence Read Archive (SRA) with accession numbers PRJNA321113 ( $t_{0}$ in YPD and YPL), PRJNA610243 (a1t $t_{100}$ in YPD), PRJNA610597 (a1t 100 , in YPL), PRJNA610474 (Da1t 110 , in YPD) and PRJNA610717 (La1t 110 , in YPL).

Acknowledgments: This paper is dedicated to the memory of Mario, who passed away too early, and who was unable to see these results. The authors would like to thank the valuable help of Jesus Navarro, our research assistant, now working outside academia.

Conflicts of Interest: The authors declare no conflict of interest. The funders had no role in the design of the study; in the collection, analyses, or interpretation of data; in the writing of the manuscript, or in the decision to publish the results in this journal. 


\section{References}

1. Rodrigues, F.; Ludovico, P.; Leão, C. Sugar metabolism in yeasts: An overview of aerobic and anaerobic glucose catabolism. In Biodiversity and Ecophysiology of Yeasts; Péter, G., Rosa, C., Eds.; Springer: Berlin/Heidelberg, Germany, 2006; pp. 101-121, ISBN 978-3-540-30985-7.

2. Smets, B.; Ghillebert, R.; De Snijder, P.; Binda, M.; Swinnen, E.; De Virgilio, C.; Winderickx, J. Life in the midst of scarcity: Adaptations to nutrient availability in Saccharomyces cerevisiae. Curr. Genet. 2010, 56, 1-32. [CrossRef]

3. Pereira, R.; Wei, Y.; Mohamed, E.; Radi, M.; Malina, C.; Herrgård, M.J.; Feist, A.M.; Nielsen, J.; Chen, Y. Adaptive laboratory evolution of tolerance to dicarboxylic acids in Saccharomyces cerevisiae. Metab. Eng. 2019, 56, 130-141. [CrossRef]

4. Hallsworth, J.E. Stress-free microbes lack vitality. Fungal Biol. 2018, 122, 379-385. [CrossRef] [PubMed]

5. Wolfe, K.H.; Shields, D.C. Molecular evidence for an ancient duplication of the entire yeast genome. Nature 1997, 387, 708-713. [CrossRef] [PubMed]

6. Marcet-Houben, M.; Gabaldón, T. Beyond the whole-genome duplication: Phylogenetic evidence for an ancient interspecies hybridization in the baker's yeast lineage. PLoS Biol. 2015, 13, e1002220. [CrossRef]

7. Nepi, M.; Calabrese, D.; Guarnieri, M.; Giordano, E. Evolutionary and ecological considerations on nectar-mediated tripartite interactions in angiosperms and their relevance in the mediterranean basin. Plants 2021, 10, 507. [CrossRef] [PubMed]

8. Dashko, S.; Zhou, N.; Compagno, C.; Piškur, J. Why, when, and how did yeast evolve alcoholic fermentation? FEMS Yeast Res. 2014, 14, 826-832. [CrossRef] [PubMed]

9. Hagman, A.; Piškur, J. A study on the fundamental mechanism and the evolutionary driving forces behind aerobic fermentation in yeast. PLoS ONE 2015, 10, 1-24. [CrossRef]

10. Wolfe, K.H. Origin of the yeast whole-genome duplication. PLoS Biol. 2015, 13, e1002221. [CrossRef]

11. Macías, L.G.; Morard, M.; Toft, C.; Barrio, E. Comparative genomics between Saccharomyces kudriavzevii and S. cerevisiae applied to identify mechanisms involved in adaptation. Front. Genet. 2019, 10, 187. [CrossRef] [PubMed]

12. Morard, M.; Benavent-Gil, Y.; Ortiz-Tovar, G.; Pérez-Través, L.; Querol, A.; Toft, C.; Barrio, E. Genome structure reveals the diversity of mating mechanisms in Saccharomyces cerevisiae $\mathrm{x}$ Saccharomyces kudriavzevii hybrids, and the genomic instability that promotes phenotypic diversity. Microb. Genom. 2020, 6, e000333. [CrossRef]

13. Morard, M.; Ibáñez, C.; Adam, A.C.; Querol, A.; Barrio, E.; Toft, C. Genomic instability in an interspecific hybrid of the genus Saccharomyces: A matter of adaptability. Microb. Genom. 2020, 6, mgen000448. [CrossRef]

14. Ohno, S. Evolution by Gene Duplication; Springer: New York, NY, USA, 1970; ISBN 978-3-642-86661-6.

15. Hakes, L.; Pinney, J.W.; Lovell, S.C.; Oliver, S.G.; Robertson, D.L. All duplicates are not equal: The difference between small-scale and genome duplication. Genome Biol. 2007, 8, R209. [CrossRef]

16. Farrè, D.; Albà, M.M. Heterogeneous patterns of gene-expression diversification in mammalian gene duplicates. Mol. Biol. Evol. 2010, 27, 325-335. [CrossRef]

17. Plata, G.; Vitkup, D. Genetic robustness and functional evolution of gene duplicates. Nucleic Acids Res. 2014, 42, 2405-2414. [CrossRef] [PubMed]

18. Toll-Riera, M.; San Millan, A.; Wagner, A.; MacLean, R.C. The genomic basis of evolutionary innovation in Pseudomonas aeruginosa. PLoS Genet. 2016, 12, 1-21. [CrossRef] [PubMed]

19. Zhao, T.; Zwaenepoel, A.; Xue, J.Y.; Kao, S.M.; Li, Z.; Schranz, M.E.; Van de Peer, Y. Whole-genome microsynteny-based phylogeny of Angiosperms. Nat. Commun. 2021, 12, 1-14. [CrossRef]

20. Fares, M.A. Survival and innovation: The role of mutational robustness in evolution. Biochimie 2015, 119, 254-261. [CrossRef]

21. Fares, M.A.; Keane, O.M.; Toft, C.; Carretero-Paulet, L.; Jones, G.W. The roles of whole-genome and small-scale duplications in the functional specialization of Saccharomyces cerevisiae Genes. PLoS Genet. 2013, 9, e1003176. [CrossRef]

22. Keane, O.M.; Toft, C.; Carretero-Paulet, L.; Jones, G.W.; Fares, M.A. Preservation of genetic and regulatory robustness in ancient gene duplicates of Saccharomyces cerevisiae. Genome Res. 2014, 24, 1830-1841. [CrossRef] [PubMed]

23. Fares, M.A.; Sabater-Muñoz, B.; Toft, C. Genome mutational and transcriptional hotspots are traps for duplicated genes and sources of adaptations. Genome Biol. Evol. 2017, 9, 1229-1240. [CrossRef]

24. Mattenberger, F.; Sabater-Muñoz, B.; Toft, C.; Sablok, G.; Fares, M.A. Expression properties exhibit correlated patterns with the fate of duplicated genes, their divergence, and transcriptional plasticity in Saccharomycotina. DNA Res. 2017, 24, 559-570. [CrossRef]

25. Khaladkar, M.; Hannenhalli, S. Functional divergence of gene duplicates-A domain-centric view. BMC Evol. Biol. 2012, 12, 126. [CrossRef] [PubMed]

26. Sabater-Muñoz, B.; Mattenberger, F.; Fares, M.A.; Toft, C. Transcriptional rewiring, adaptation, and the role of gene duplication in the metabolism of ethanol of Saccharomyces cerevisiae. mSystems 2020, 5, e00416-20. [CrossRef]

27. Mattenberger, F.; Sabater-Muñoz, B.; Hallsworth, J.E.; Fares, M.A. Glycerol stress in Saccharomyces cerevisiae: Cellular responses and evolved adaptations. Environ. Microbiol. 2017, 19, 990-1007. [CrossRef] [PubMed]

28. Skoneczny, M.; Skoneczna, A. Response mechanisms to chemical and physical stresses in yeast and filamentous fungi. In Stress Response Mechanisms in Fungi: Theoretical and Practical Aspects; Skoneczny, M., Ed.; Springer International Publishing: Cham, Switzerland, 2018; pp. 35-85, ISBN 978-3-030-00682-2.

29. Casal, M.; Paiva, S.; Queirós, O.; Soares-Silva, I. Transport of carboxylic acids in yeasts. FEMS Microbiol. Rev. 2008, 32, 974-994. [CrossRef] 
30. Pereira, R.; Mohamed, E.T.; Radi, M.S.; Herrgård, M.J.; Feist, A.M.; Nielsen, J.; Chen, Y. Elucidating aromatic acid tolerance at low $\mathrm{pH}$ in Saccharomyces cerevisiae using adaptive laboratory evolution. Proc. Natl. Acad. Sci. USA 2020, 117, 27954-27961. [CrossRef]

31. Jarboe, L.R.; Royce, L.A.; Liu, P. Understanding biocatalyst inhibition by carboxylic acids. Front. Microbiol. 2013, 4, 1-8. [CrossRef]

32. Sprouffske, K.; Wagner, A. Growthcurver: An R package for obtaining interpretable metrics from microbial growth curves. BMC Bioinform. 2016, 17, 172. [CrossRef] [PubMed]

33. Conway, J.R.; Lex, A.; Gehlenborg, N. UpSetR: An R package for the visualization of intersecting sets and their properties. Bioinformatics 2017, 33, 2938-2940. [CrossRef]

34. Yu, G.; Wang, L.G.; Han, Y.; He, Q.Y. ClusterProfiler: An R package for comparing biological themes among gene clusters. OMICS J. Integr. Biol. 2012, 16, 284-287. [CrossRef]

35. Carretero-Paulet, L.; Albert, V.A.; Fares, M.A. Molecular evolutionary mechanisms driving functional diversification of the HSP90A family of heat shock proteins in eukaryotes. Mol. Biol. Evol. 2013, 30, 2035-2043. [CrossRef] [PubMed]

36. Skoneczny, M. Stress Response Mechanisms in Fungi; Springer International Publishing: Cham, Switzerland, 2018; ISBN 978-3-03000682-2.

37. Brooks, G.A. The science and translation of lactate shuttle theory. Cell Metab. 2018, 27, 757-785. [CrossRef]

38. Kiran, D.; Basaraba, R.J. Lactate metabolism and signaling in tuberculosis and cancer: A comparative review. Front. Cell. Infect. Microbiol. 2021, 11, 1-24. [CrossRef]

39. Gladden, L.B. Lactate metabolism: A new paradigm for the third millennium. J. Physiol. 2004, 558, 5-30. [CrossRef]

40. Dong, S.; Qian, L.; Cheng, Z.; Chen, C.; Wang, K.; Hu, S.; Zhang, X.; Wu, T. Lactate and myocadiac energy metabolism. Front. Physiol. 2021, 12, 1-12. [CrossRef] [PubMed]

41. Piper, P.; Calderon, C.O.; Hatzixanthis, K.; Mollapour, M. Weak acid adaptation: The stress response that confers yeasts with resistance to organic acid food preservatives. Microbiology 2001, 147, 2635-2642. [CrossRef] [PubMed]

42. Venkataram, S.; Dunn, B.; Li, Y.; Agarwala, A.; Chang, J.; Ebel, E.R.; Geiler-Samerotte, K.; Hérissant, L.; Blundell, J.R.; Levy, S.F.; et al. Development of a comprehensive genotype-to-fitness map of adaptation-driving mutations in yeast. Cell 2016, 166, 1585-1596.e22. [CrossRef] [PubMed]

43. Baek, S.H.; Kwon, E.Y.; Bae, S.J.; Cho, B.R.; Kim, S.Y.; Hahn, J.S. Improvement of d-Lactic acid production in Saccharomyces cerevisiae under acidic conditions by evolutionary and rational metabolic engineering. Biotechnol. J. 2017, 12, 1-7. [CrossRef] [PubMed]

44. Filteau, M.; Hamel, V.; Pouliot, M.; Gagnon-Arsenault, I.; Dubé, A.K.; Landry, C.R. Evolutionary rescue by compensatory mutations is constrained by genomic and environmental backgrounds. Mol. Syst. Biol. 2015, 11, 832. [CrossRef]

45. Rosenberg, S.M. Evolving responsively: Adaptive mutation. Nat. Rev. Genet. 2001, 2, 504-515. [CrossRef] [PubMed]

46. Payen, C.; Sunshine, A.B.; Ong, G.T.; Pogachar, J.L.; Zhao, W.; Dunham, M.J. High-throughput identification of adaptive mutations in experimentally evolved yeast populations. PLoS Genet. 2016, 12, e1006339. [CrossRef] [PubMed]

47. Fisher, K.J.; Buskirk, S.W.; Vignogna, R.C.; Marad, D.A.; Lang, G.I. Adaptive genome duplication affects patterns of molecular evolution in Saccharomyces cerevisiae. PLoS Genet. 2018, 14, e1007396. [CrossRef] [PubMed]

48. Buskirk, S.W.; Rokes, A.B.; Lang, G.I. Adaptive evolution of nontransitive fitness in yeast. eLife 2020, 9, e62238. [CrossRef]

49. Zan, Y.; Carlborg, Ö. Dissecting the genetic regulation of yeast growth plasticity in response to environmental changes. Genes 2020, 11, 1279. [CrossRef]

50. Petrizzelli, M.S.; de Vienne, D.; Nidelet, T.; Noûs, C.; Dillmann, C. Data integration uncovers the metabolic bases of phenotypic variation in yeast. PLoS Comput. Biol. 2021, 17, e1009157. [CrossRef]

51. Hewitt, S.K.; Foster, D.S.; Dyer, P.S.; Avery, S.V. Phenotypic heterogeneity in fungi: Importance and methodology. Fungal Biol. Rev. 2016, 30, 176-184. [CrossRef]

52. Yi, X.; Dean, A.M. Phenotypic plasticity as an adaptation to a functional trade-off. eLife 2016, 5, e19307. [CrossRef]

53. Pacheco, A.; Talaia, G.; Sá-Pessoa, J.; Bessa, D.; Gonçalves, M.J.; Moreira, R.; Paiva, S.; Casal, M.; Queirós, O. Lactic acid production in Saccharomyces cerevisiae is modulated by expression of the monocarboxylate transporters Jen1 and Ady2. FEMS Yeast Res. 2012, 12, 375-381. [CrossRef]

54. Dato, L.; Berterame, N.M.; Ricci, M.A.; Paganoni, P.; Palmieri, L.; Porro, D.; Branduardi, P. Changes in SAM2 expression affect lactic acid tolerance and lactic acid production in Saccharomyces cerevisiae. Microb. Cell Fact. 2014, 13, 147. [CrossRef]

55. Kang, K.; Bergdahl, B.; MacHado, D.; Dato, L.; Han, T.L.; Li, J.; Villas-Boas, S.; Herrgård, M.J.; Förster, J.; Panagiotou, G. Linking genetic, metabolic, and phenotypic diversity among Saccharomyces cerevisiae strains using multi-omics associations. Gigascience 2019, 8, giz015. [CrossRef]

56. Ferea, T.L.; Botstein, D.; Brown, P.O.; Rosenzweig, R.F. Systematic changes in gene expression patterns following adaptive evolution in yeast. Proc. Natl. Acad. Sci. USA 1999, 96, 9721-9726. [CrossRef]

57. Taymaz-Nikerel, H.; Cankorur-Cetinkaya, A.; Kirdar, B. Genome-wide transcriptional response of Saccharomyces cerevisiae to stress-induced perturbations. Front. Bioeng. Biotechnol. 2016, 4, 17. [CrossRef] [PubMed]

58. Turcotte, B.; Liang, X.B.; Robert, F.; Soontorngun, N. Transcriptional regulation of nonfermentable carbon utilization in budding yeast. FEMS Yeast Res. 2010, 10, 2-13. [CrossRef] [PubMed]

59. Gasmi, N.; Jacques, P.E.; Klimova, N.; Guo, X.; Ricciardi, A.; Robert, F.; Turcotte, B. The switch from fermentation to respiration in Saccharomyces cerevisiae is regulated by the Ert1 transcriptional activator/repressor. Genetics 2014, 198, 547-560. [CrossRef] [PubMed] 
60. Ortiz-Merino, R.A.; Kuanyshev, N.; Byrne, K.P.; Varela, J.A.; Morrissey, J.P.; Porro, D.; Wolfe, K.H.; Branduardi, P. Transcriptional response to lactic acid stress in the hybrid yeast Zygosaccharomyces parabailii. Appl. Environ. Microbiol. 2017, 84, e02294-17. [CrossRef] [PubMed]

61. Zhang, J. Evolution by gene duplication: An update. Trends Ecol. Evol. 2003, 18, 292-298. [CrossRef]

62. Cui, L.; Wall, P.K.; Leebens-Mack, J.H.; Lindsay, B.G.; Soltis, D.E.; Doyle, J.J.; Soltis, P.S.; Carlson, J.E.; Arumuganathan, K.; Barakat, A.; et al. Widespread genome duplications throughout the history of flowering plants. Genome Res. 2006, 16, 738-749. [CrossRef]

63. Panchy, N.; Lehti-Shiu, M.; Shiu, S. Evolution of gene duplication in plants. Plant Physiol. 2016, 171, 2294-2316. [CrossRef] [PubMed]

64. Jaillon, O.; Aury, J.M.; Wincker, P. "Changing by doubling", the impact of whole genome duplications in the evolution of eukaryotes. Comptes Rendus Biol. 2009, 332, 241-253. [CrossRef]

65. Freeling, M.; Thomas, B.C. Gene-balanced duplications, like tetraploidy, provide predictable drive to increase morphological complexity. Genome Res. 2006, 16, 805-814. [CrossRef] [PubMed]

66. Voordeckers, K.; Verstrepen, K.J. Experimental evolution of the model eukaryote Saccharomyces cerevisiae yields insight into the molecular mechanisms underlying adaptation. Curr. Opin. Microbiol. 2015, 28, 1-9. [CrossRef] [PubMed]

67. Stern, S.; Dror, T.; Stolovicki, E.; Brenner, N.; Braun, E. Genome-wide transcriptional plasticity underlies cellular adaptation to novel challenge. Mol. Syst. Biol. 2007, 3, 106. [CrossRef]

68. Nguyen Ba, A.N.; Cvijović, I.; Rojas Echenique, J.I.; Lawrence, K.R.; Rego-Costa, A.; Liu, X.; Levy, S.F.; Desai, M.M. Highresolution lineage tracking reveals travelling wave of adaptation in laboratory yeast. Nature 2019, 575, 494-499. [CrossRef] [PubMed]

69. Dejean, L.; Beauvoit, B.; Guérin, B.; Rigoulet, M. Growth of the yeast Saccharomyces cerevisiae on a non-fermentable substrate: Control of energetic yield by the amount of mitochondria. Biochim. Biophys. Acta Bioenerg. 2000, 1457, 45-56. [CrossRef]

70. Orij, R.; Brul, S.; Smits, G.J. Intracellular pH is a tightly controlled signal in yeast. Biochim. Biophys. Acta Gen. Subj. 2011, 1810, 933-944. [CrossRef]

71. Bergthorsson, U.; Andersson, D.I.; Roth, J.R. Ohno's dilemma: Evolution of new genes under continuous selection. Proc. Natl. Acad. Sci. USA 2007, 104, 17004-17009. [CrossRef]

72. Maslov, S.; Sneppen, K.; Eriksen, K.A.; Yan, K.-K. Upstream plasticity and downstream robustness in evolution of molecular networks. BMC Evol. Biol. 2004, 4, 9. [CrossRef] [PubMed]

73. R Core Team. R: A Language and Environment for Statistical Computing; R Core Team: Vienna, Austria, 2020.

74. Mattenberger, F.; Sabater-Muñoz, B.; Toft, C.; Fares, M.A. The phenotypic plasticity of duplicated genes in Saccharomyces cerevisiae and the origin of adaptations. G3 Genes Genomes Genet. 2017, 7, 63-75. [CrossRef]

75. Robinson, M.D.; McCarthy, D.J.; Smyth, G.K. edgeR: A Bioconductor package for differential expression analysis of digital gene expression data. Bioinformatics 2010, 26, 139-140. [CrossRef]

76. Byrne, K.P.; Wolfe, K.H. The Yeast Gene Order Browser: Combining curated homology and syntenic context reveals gene fate in polyploid species. Genome Res. 2005, 15, 1456-1461. [CrossRef] [PubMed] 